\title{
Bioinspired Catalytic Generation of Main- group Electrophiles by Cooperative Bond Activation
}

\author{
Francis Forster and Martin Oestreich*
}

\begin{abstract}
Catalytic processes involving cooperativity have seen tremendous progress in recent years and impressive new synthetic methodologies have been developed. Inspired by the cooperative heterolytic $\mathrm{H}_{2}$ splitting in [NiFe] hydrogenases, Ohki and Tatsumi designed cationic ruthenium thiolate complexes with a tethered sulfur ligand. Over the last decade, we have demonstrated the facile activation of main-group hydrides such as hydrosilanes, hydroboranes, DIBAL-H, and hydrostannanes by the Ru-S bond in Ohki-Tatsumi complexes. This account illustrates these E-H bond activations and highlights selected catalytic applications, particularly dehydrocouplings, of the generated main-group electrophiles.
\end{abstract}

Keywords: C-H Functionalization · Cooperative catalysis · Dehydrogenative couplings · Main-group electrophiles

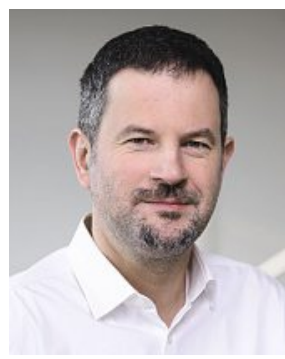

Martin Oestreich (born in 1971 in Pforzheim/Germany) is Professor of Organic Chemistry at the Technische Universität Berlin. $\mathrm{He}$ received his diploma degree with Paul Knochel (Marburg, 1996) and his doctoral degree with Dieter Hoppe (Münster, 1999). After a two-year postdoctoral stint with Larry E. Overman (Irvine, 1999-2001), he completed his habilitation with Reinhard Brückner (Freiburg, 2001-2005) and was appointed as Professor of Organic Chemistry at the Westfälische Wilhelms-Universität Münster (20062011). He also held visiting positions at Cardiff University in Wales (2005) and at The Australian National University in Canberra (2010). Photo: CTU Berlin/Phil Dera

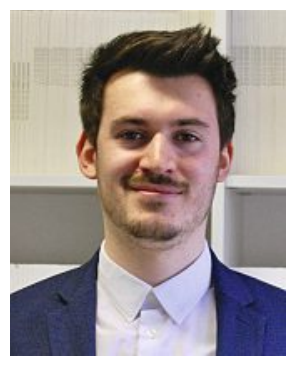

Francis Forster (born 1990 in Berlin/ Germany) studied chemistry at the Technische Universität Berlin (20102015) where he obtained his bachelor degree with Martin Oestreich (2013). After a three-month internship at HoffmannLa Roche (Basel/Switzerland) he finished his master degree (2015) with Martin Oestreich and is currently a graduate student in the same group. Photo: CTU Berlin/ Julien Fuchs

\section{Introduction}

Knowledge of biochemical processes and their underlying mechanisms is a source of inspiration for the invention of new synthetic transformations. Cooperative bond activation involving metal-ligand cooperation is one such example. ${ }^{[1]}$ Metal-sulfur bonds ${ }^{[2]}$ as found in $[\mathrm{NiFe}]$ hydrogenases are able to cooperatively split $\mathrm{H}_{2}$ (Scheme 1, left). ${ }^{[3]}$ The heterolysis of $\mathrm{H}_{2}$ presumably occurs at the $\mathrm{Ni}-\mathrm{S}(\mathrm{Cys})$ bond of the active site of the $[\mathrm{NiFe}]$ hydrogenase, resulting in the formation of a nickel hydride and a protonated sulfur ligand. Reactions of this type can also be viewed as small-molecule activation by a transition-metal frustrated Lewis pair (FLP). ${ }^{[4]}$ This fascinating insight stimulated us to investigate the generation of main-group electrophiles such as silylium, borenium, alumenium, and stannylium ions by heterolytic cleavage of $\mathrm{E}-\mathrm{H}$ bonds $\left(\mathrm{E}=\mathrm{SiR}_{3}, \mathrm{BR}_{2}, \mathrm{AlR}_{2}\right.$, and $\mathrm{SnR}_{3}$ ). Ohki and Tatsumi had designed mononuclear catalysts containing Power's SDmp ligand[5] (Dmp = 2,6-dimesitylphenyl) to mimic hydrogenase-like $\mathrm{H}_{2}$ splitting (Scheme 1, right). ${ }^{\text {[6a] Rhodium }}$ complex $[\mathbf{1}]^{+}\left[\mathrm{BAr}_{4}^{\mathrm{F}}\right]^{-}$and iridium complex $[2]^{+}\left[\mathrm{BAr}^{\mathrm{F}}\right]^{-}$were particularly active, promoting the $\mathrm{H}_{2}$ heterolysis even at cryostatic temperatures.

However, dissociation of the SDmp ligand occurred after the bond-activation event but tethering one of the mesityl groups of the SDmp ligand to the metal center prevented this problem. This is realized in ruthenium complexes $[3]^{+}[\mathrm{X}]^{-}$ (Scheme 2), and Ohki and Tatsumi demonstrated the cooperative activation of $\mathrm{H}_{2}$ by $[3]^{+}\left[\mathrm{BAr}_{4}^{\mathrm{F}}\right]^{-}$in the hydrogenation of acetophenone to 1-phenylethanol (not shown). ${ }^{[7]}$ Together with Ohki and Tatsumi, we have employed complexes $[3]^{+}[\mathrm{X}]^{-}$for cooperative $\mathrm{Si}-\mathrm{H}^{[8-12]}$ as well as $\mathrm{B}-\mathrm{H}^{[13]}$ and, more recently, $\mathrm{Al}-\mathrm{H}^{[14]}$ as well as $\mathrm{Sn}-\mathrm{H}^{[15]}$ bond activation (Scheme 2, left). The Ru-S bond in $[3]^{+}[\mathrm{X}]^{-}$was shown to split E-H bonds heterolytically into a hydride and the corresponding proton or main-group cation. The molecular structures of three of these adducts were secured by X-ray diffraction (Scheme 2, right). The hydrosilane adduct $\left[\mathbf{3 a} \cdot \mathrm{EtMe}_{2} \mathrm{SiH}\right]^{+}\left[\mathrm{BAr}^{\mathrm{F}}\right]_{4}^{-}$ showed complete cleavage of the $\mathrm{Si}-\mathrm{H}$ bond ( $\mathrm{Si} \cdots \mathrm{H}$ distance: $3.27 \AA$ ) whereas both the hydroborane adduct [3a.9$\mathrm{BBN}]^{+}\left[\mathrm{BAr}^{\mathrm{F}}\right]_{4}^{-}$and the hydroalane adduct $\left[3 \mathbf{a} \cdot i \mathrm{Bu}_{2} \mathrm{AlH}\right]^{+}\left[\mathrm{B}\left(\mathrm{C}_{6} \mathrm{~F}_{5}\right)_{4}\right]^{-}$still exhibited bonding character between the $\mathrm{E}$ and the $\mathrm{H}$ atoms (B-H bond length: $1.55 \AA$ and Al-H bond length: $2.16 \AA$ ). Additionally, 
for adduct $\left[\mathbf{3 a} \cdot i \mathrm{Bu} \mathrm{AlH}_{2} \mathrm{AlH}\right]^{+}\left[\mathrm{B}\left(\mathrm{C}_{6} \mathrm{~F}_{5}\right)_{4}\right]^{-}$a $\mathrm{Ru} \cdots \mathrm{Al}$ interaction was observed $(\mathrm{Ru} \cdots \mathrm{Al}$ distance: $2.78 \AA$ A). Quantum-chemical calculations describe this bonding situation as a three-center-two-electron $(3 \mathrm{c} 2 \mathrm{e})$ donor-acceptor $\sigma(\mathrm{Ru}-\mathrm{H}) \rightarrow \mathrm{Al}$ interaction. In this account article, the application of these sulfur-stabilized main-group cations in catalysis will be discussed with an emphasis on dehydrogenative coupling reactions.

\section{Dehydrogenative Silylation and Borylation of $\mathrm{C}\left(\mathbf{s p}^{2}\right)-\mathrm{H}$ Bonds}

Extensive experimental and computational studies concerning the cooperative $\mathrm{Si}-\mathrm{H}$ bond activation with $[3]^{+}\left[\mathrm{BAr}_{4}^{\mathrm{F}}\right]^{-}$ were carried out. ${ }^{[8 b]}$ NMR spectroscopic analysis of the hydrosilane adducts $\left[3 \cdot \mathrm{R}_{3} \mathrm{SiH}\right]^{+}\left[\mathrm{BAr}_{4}^{\mathrm{F}}\right]^{-}$showed a diagnostic hydride resonance of $\delta\left({ }^{1} \mathrm{H}\right) \approx-8.0 \mathrm{ppm}$ and ${ }^{2} J_{\mathrm{H}, \mathrm{P}}$ coupling constants of $\sim 49 \mathrm{~Hz}$. The corresponding sulfur-stabilized silylium ions had chemical shifts in the range of $\delta\left({ }^{29} \mathrm{Si}\right) \approx 18-42 \mathrm{ppm}$. The first example of a catalysis by ruthenium complexes $[3]^{+}\left[\mathrm{BAr}_{4}^{\mathrm{F}}\right]^{-}$involving sulfur-stabilized silicon electrophiles was the dehydrogenative silylation of $\mathrm{N}$-protected indoles $4 \mathbf{( 4} \rightarrow \mathbf{5}$, Scheme 3, left). ${ }^{[9]}$ Cooperative $\mathrm{Si}-\mathrm{H}$ bond activation combined with electrophilic aromatic substitution $\left(\mathrm{S}_{\mathrm{E}} \mathrm{Ar}\right)$ afforded the $\mathrm{C} 3$-silylated indoles $\mathbf{5}$ exclusively. It was shown that various alkyl and halogen substituents in different positions of the arene ring were well tolerated, as was substitution at $\mathrm{C} 2$.

A few years later, we accomplished the cooperative activation of $\mathrm{B}-\mathrm{H}$ bonds in hydroboranes using catalysts $[3]^{+}\left[\mathrm{BAr}^{\mathrm{F}}\right]_{4}^{-}$ to generate sulfur-stabilized borenium ions. ${ }^{[13]}$ For alkyl-substituted boranes, adducts $\left[3 \cdot \mathrm{R}_{2} \mathrm{BH}\right]^{+}\left[\mathrm{BAr}{ }_{4}\right]^{-}$showed hydride shifts of $\delta\left({ }^{1} \mathrm{H}\right) \approx-12.0 \mathrm{ppm}$ and ${ }^{2} J_{\mathrm{H}}$ coupling constants of $\sim 18 \mathrm{~Hz}$. Activation of oxygen-substituted boranes such as pinacolborane (pinBH) and catecholborane (catBH) was also achieved; the corresponding chemical shifts of the hydride were shifted to higher field and coupling constants were larger. Detection of the ${ }^{11} \mathrm{~B}$ nuclei in adducts $\left[3 \cdot \mathrm{R}_{2} \mathrm{BH}\right]^{+}\left[\mathrm{BAr}_{4}^{\mathrm{F}}\right]^{-}$was not feasible because of rapid quadrupolar relaxation. Analogously to the dehydrogenative $\mathrm{C}-\mathrm{H}$ silylation, these boron electrophiles engaged in the dehydrogenative borylation of $\mathrm{N}$-protected indoles $\mathbf{4}$ to furnish C3-borylated indoles $\mathbf{6}$ with excellent regioselectivity $\left(\mathbf{4} \rightarrow \mathbf{6}\right.$, Scheme 3 , right) ${ }^{[13]}$ Alkyl-, dimethylamino-, and bromo-substituted indoles $\mathbf{4}$ reacted smoothly at elevated temperatures.

In contrast to $\mathrm{C}-\mathrm{H}$ bond activation typically favoring reaction at the $\mathrm{C} 2$ position of indoles, the above shown $\mathrm{C} 3$ silylation

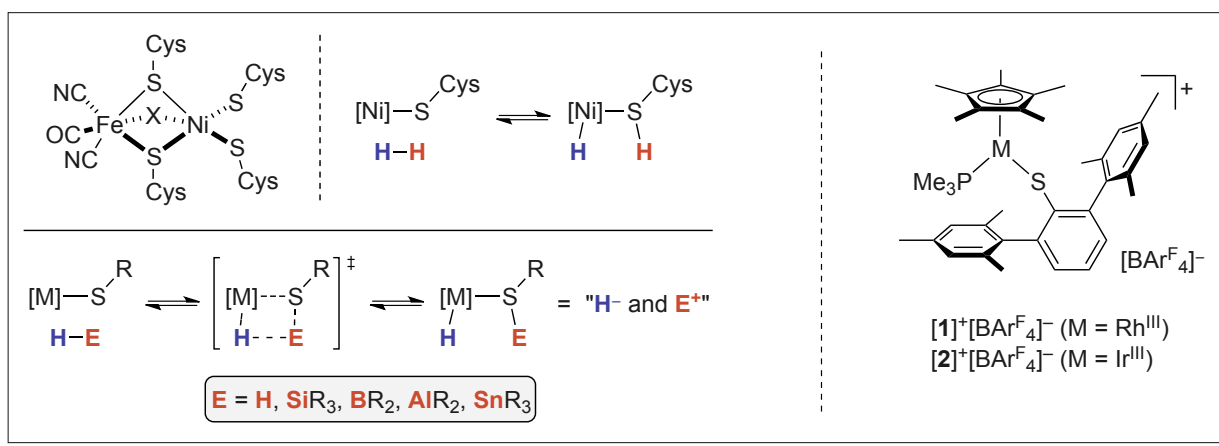

Scheme 1. Left: Active site of [NiFe] hydrogenase $\left(\mathrm{X}=\mathrm{OH}\right.$ or $\mathrm{O}$, Cys = cysteine), assumed $\mathrm{H}_{2}$ heterolysis (top), and cooperative activation of $\mathrm{E}-\mathrm{H}$ bonds at transition metal-sulfur bonds (bottom). Right: Cationic complexes for cooperative activation of dihydrogen developed by Ohki and Tatsumi. ArF = 3,5-bis(trifluoromethyl)phenyl.

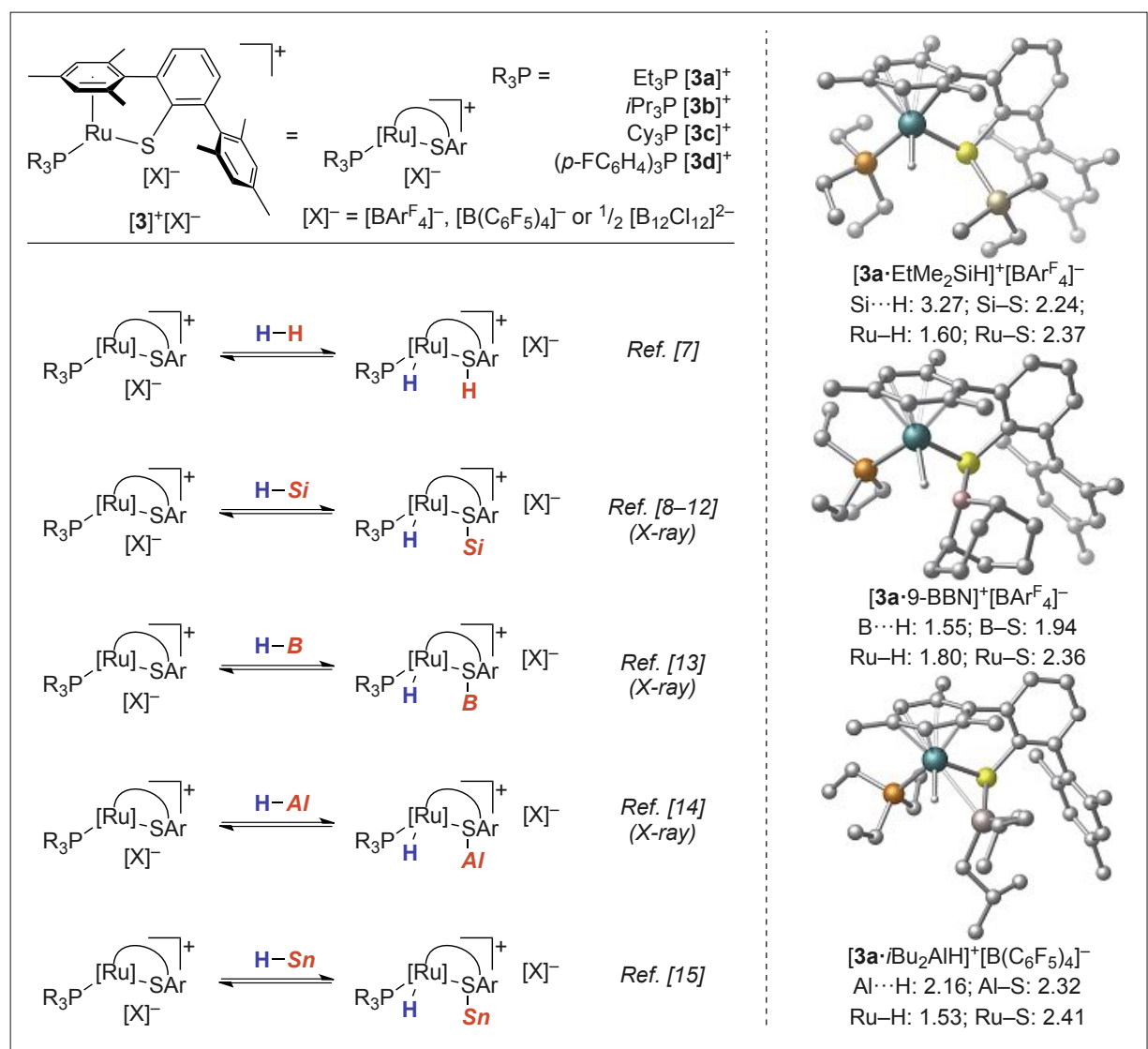

Scheme 2. Left: Tethered Ru-S complexes $[3]^{+}[\mathrm{X}]^{-}$and cooperative bond activation of $\mathrm{E}-\mathrm{H}$ bonds $[\mathrm{E}=\mathrm{H}, \mathrm{Si}, \mathrm{B}, \mathrm{Al}$, and $\mathrm{Sn}]$. Right: Molecular structures of [3a.EtMe $\mathrm{SiH}^{+}\left[\mathrm{BAr}{ }_{4}\right]^{-}$(top, reproduced from ref. [8b] with permission from the Royal Society of Chemistry), [3a-9-BBN] ${ }^{+}\left[\mathrm{BAr}_{4}{ }_{4}\right]^{-}$ (middle, reprinted with permission from ref. [13]. Copyright 2013 American Chemical Society), $\left[3 a \cdot i \mathrm{Bu}_{2} \mathrm{AlH}\right]^{+}\left[\mathrm{B}\left(\mathrm{C}_{6} \mathrm{~F}_{5}\right)_{4}\right]^{-}$(bottom, reprinted with permission from ref. [14]. Copyright 2017 American Chemical Society). Counteranions in the crystal structures omitted for clarity. Bond lengths given in $\AA$.

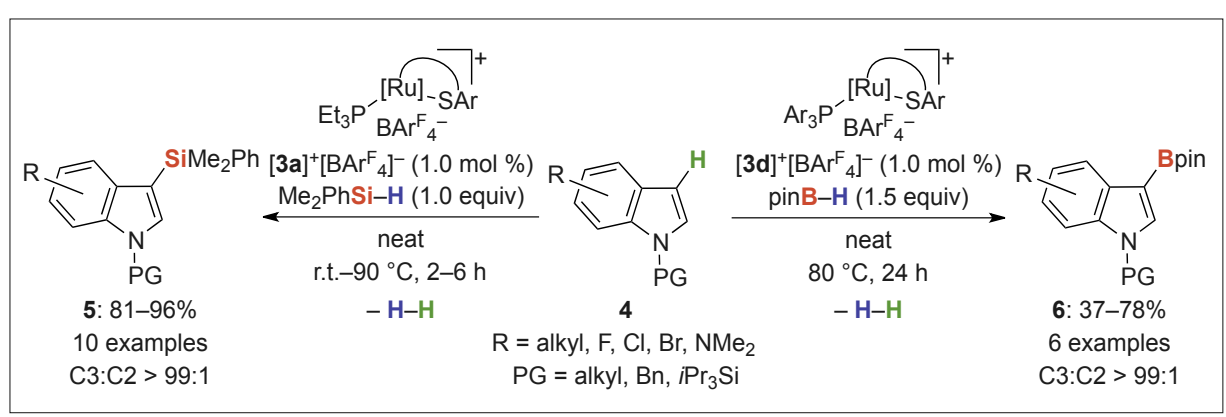

Scheme 3. Intermolecular electrophilic $\mathrm{C}-\mathrm{H}$ silylation (left) and borylation (right) of N-protected indoles. $\mathrm{Ar}_{3} \mathrm{P}=\left(\mathrm{p}-\mathrm{FC}_{6} \mathrm{H}_{4}\right)_{3} \mathrm{P}$. 
or borylation is the result of electronic control, as expected for an $\mathrm{S}_{\mathrm{E}} \mathrm{Ar}$ mechanism. ${ }^{[16]}$ If the $\mathrm{C} 3$ position is occupied by a methyl group, the $\mathrm{C} 2$-silylated or -borylated indoles 5 or $\mathbf{6}$ were not obtained. The use of a deuterated hydrosilane or hydroborane helped to exclude a pathway involving hydrosilylation or hydroboration followed by indoline-to-indole oxidation as no deuterium incorporation at $\mathrm{C} 2$ was observed. A plausible catalytic cycle is depicted in Scheme 4. The $\mathrm{Ru}-\mathrm{S}$ bond cooperatively activates the E-H bond $\left([3]^{+} \rightarrow\left[3 \cdot \mathrm{R}_{\mathrm{n}} \mathrm{EH}\right]^{+}\right)$, and subsequent transfer of the main-group cation to indole $\mathbf{4}$ gives the Wheland intermediate $[\mathbf{8}]^{+}\left(\mathbf{4} \rightarrow[\mathbf{8}]^{+}\right)$ along with the neutral ruthenium hydride $7\left(\left[3 \cdot \mathrm{R}_{\mathrm{n}} \mathrm{EH}\right]^{+} \rightarrow \mathbf{7}\right)$. Deprotonation of $[8]^{+}$ by the weakly basic sulfur atom in 7 then yields the C3-functionalized indoles 5 or $6\left([8]^{+} \rightarrow 5 / 6\right)$ and the dihydrogen adduct $\left[3 \cdot \mathrm{H}_{2}\right]^{+}\left(7 \rightarrow\left[3 \cdot \mathrm{H}_{2}\right]^{+}\right)$. The latter immediately releases $\mathrm{H}_{2}$, thereby regenerating the active catalyst $[\mathbf{3}]^{+}$and closing the catalytic cycle $\left(\left[3 \cdot \mathrm{H}_{2}\right]^{+} \rightarrow[3]^{+}\right)$.

We anticipated that an intramolecular $\mathrm{C}-\mathrm{H}$ silylation of less nucleophilic benzenes by the same mechanism would convert ortho-silylated biphenyls 9 into dibenzosiloles 10 (Scheme 5). ${ }^{[9 b]}$ Under more forcing conditions, quite remarkable functional-group tolerance was demonstrated. Biphenyls 9 efficiently underwent the ring closure, thereby providing rapid access to dibenzosiloles $\mathbf{1 0}$ functionalized at both phenylene groups. By combining these inter- and intramolecular electrophilic $\mathrm{C}-\mathrm{H}$ silylations, we achieved the catalytic synthesis of indole-fused benzosiloles starting from 2-aryl-substituted indoles and dihydrosilanes (not shown). ${ }^{[9 c]}$

The low hydricity of the intermediate ruthenium hydride 7 (allowing for dehy-

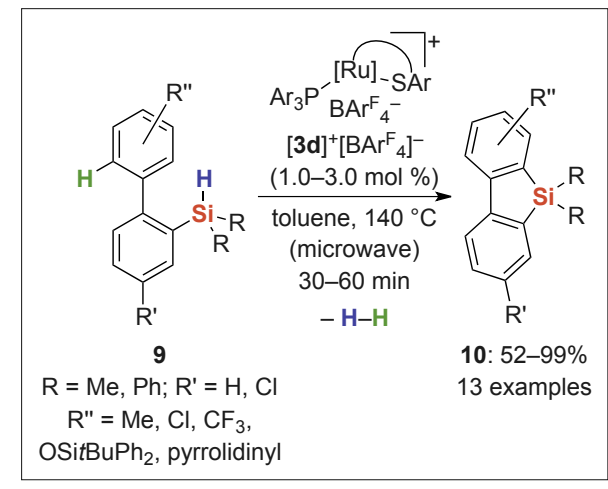

Scheme 5. Intramolecular electrophilic $\mathrm{C}-\mathrm{H}$ silylation of arenes. $\operatorname{Ar}_{3} \mathrm{P}=\left(\mathrm{p}-\mathrm{FC}_{6} \mathrm{H}_{4}\right)_{3} \mathrm{P}$.

drogenative couplings rather than hydrosilylations) led us to investigate the reactivity of enolizable ketones $\mathbf{1 1}(\mathrm{X}=\mathrm{O})$ toward the Ohki-Tatsumi complexes $[3]^{+}[\mathrm{X}]^{-}$and hydrosilanes (Scheme 6, top left). ${ }^{[10 a]}$ These reactions yielded, in the presence of catalyst $[\mathbf{3 a}]^{+}\left[\mathrm{BAr}_{4}^{\mathrm{F}}\right]^{-}$, silyl enol ethers $12(\mathbf{1 1} \rightarrow \mathbf{1 2})$ instead of the expected silyl ethers $\mathbf{1 3}$ as the major products. The substrate scope is broad and ranges from differently substituted aryl groups to purely aliphatic ketones. Increased steric hindrance, i.e., ortho-substitution in acetophenone derivatives, favored the corresponding silyl enol ethers $\mathbf{1 2}$ with significantly higher selectivity. Applying deuterated hydrosilanes in the catalysis showed deuterium incorporation in the $\alpha$-position of silyl ethers 13; we explain this by the subsequent hydrogenation of the initially formed silyl enol ether $\mathbf{1 2}$ by in situ-formed $\left[\mathbf{3 a} \cdot \mathrm{H}_{2}\right]^{+}(\mathbf{1 2} \rightarrow \mathbf{1 3}){ }^{[10 b]} \mathrm{We}$ later extended this methodology to enolizable ketimines 11 ( $\mathrm{X}=\mathrm{NPG}$ ) (Scheme 6 , top right). ${ }^{[10 c]}$ The choice of the bulkier catalyst $[3 \mathbf{b}]^{+}\left[\mathrm{BAr}_{4}^{\mathrm{F}}\right]^{-}$was crucial to suppress reduction pathways and, hence,
N-silylated enamines 14 were obtained with high chemoselectivity $(\mathbf{1 1} \rightarrow \mathbf{1 4})$. Subsequent dehydrogenative silylation of 14 did form C-silylated N-silylated enamines 15 but only in trace amounts $(14 \rightarrow 15)$, and hydrogenation of 14 to amines 16 was observed, also only in minor quantities $(\mathbf{1 4} \rightarrow \mathbf{1 6})$. When performing these reactions in closed vessels, net reduction of the $\mathrm{C}=\mathrm{X}$ bond by the aforementioned dehydrogenation-hydrogenation sequence occurred $(\mathbf{1 1} \rightarrow \mathbf{1 2} \rightarrow \mathbf{1 3}$ or $\mathbf{1 1} \rightarrow \mathbf{1 4} \rightarrow \mathbf{1 6}$, Scheme 6, top). Recently, we were able to perform enantioselective hydrogenation with either $\left.[(S)-3 \mathbf{e}]^{+}\left[\mathrm{BAr}^{\mathrm{F}}\right]_{4}\right]^{-}$, coordinated with a chiral phosphine, ${ }^{[10 \mathrm{~b}]}$ or $[(R)-\mathbf{1 7} \mathbf{a}]^{+}\left[\mathrm{BAr}_{4}^{\mathrm{F}}\right]^{-}$, based on an axial chiral SDmp derivative (Scheme 6, bottom). ${ }^{[10 \mathrm{~d}]}$ Promising levels of enantioselection were achieved: $\sim 55 \%$ ee with $[(S)-3 \mathbf{e}]^{+}\left[\mathrm{BAr}_{4}^{\mathrm{F}}\right]^{-}$ and $\sim 40 \%$ ee $\left.[(R)-\mathbf{1 7} \mathbf{a}]^{+}\left[\mathrm{BAr}^{\mathrm{F}}\right]_{4}\right]^{-}$.

After we had developed a 1,4-selective hydrosilylation of pyridines catalyzed by $[3]^{+}\left[\mathrm{BAr}_{4}^{\mathrm{F}}\right]^{-}$(not shown), [11a] we turned toward a cascade reaction consisting of this hydrosilylation, the above-described dehydrogenative enamine silylation, and retro-hydrosilylation. The overall sequence corresponds to a formal metaselective electrophilic aromatic substitution of pyridines $\mathbf{1 8}$ with hydrosilanes (Scheme 7). ${ }^{[11 \mathrm{~b}]}$ Several pyridines 18 were transformed into C3-silylated pyridines 19 with reasonable functional-group tolerance. Monitoring this three-step transformation by ${ }^{1} \mathrm{H}$ NMR spectroscopy provided the following mechanistic observations: i) The 1,4-hydrosilylation of pyridines 18 occurs already at ambient temperature, resulting in 1,4-dihydropyridines. ii) The $\mathrm{N}$-silylated enamine unit then undergoes dehydrogenative silylation in the $\beta$-position of the enamine to form the me-

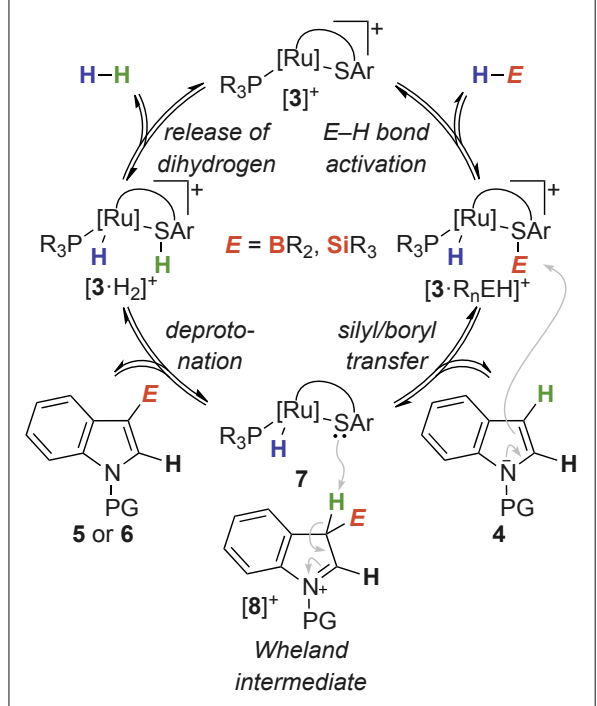

Scheme 4. Proposed mechanism for the intermolecular electrophilic $\mathrm{C}-\mathrm{H}$ silylation and borylation of $\mathrm{N}$-protected indoles 4 by $[3]^{+}\left[\mathrm{BAr}_{4}^{\mathrm{F}}\right]^{-}$. Counteranions omitted for clarity.

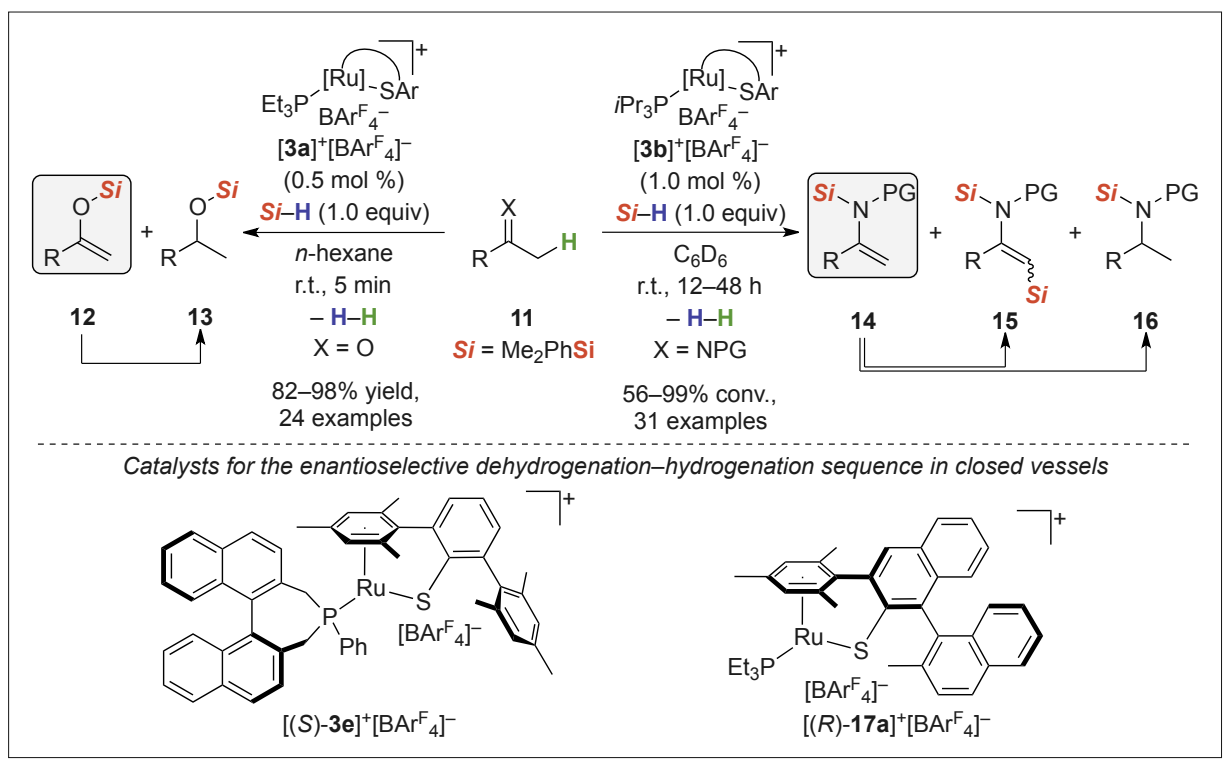

Scheme 6. Top: Dehydrogenative coupling of enolizable ketones (left) and imines (right) with hydrosilanes. Highlighted are the major products of catalysis in open vessels. Bottom: Chiral catalysts for enantioselective hydrogenations in closed vessels. 
ta-silylated 1,4-dihydropyridines. iii) The 1,4-hydrosilylation is reversible, ${ }^{[11 \mathrm{c}]}$ and these 1,4-dihydropyridines rearomatize at elevated temperature to yield the desired C3-silylated pyridines 19.

\section{Hydrodefluorination by Alumenium Ions}

Main-group electrophiles are known to mediate hydrodefluorination reactions. ${ }^{[17]}$ We had previously shown that the sulfurstabilized silylium ion generated from hydrosilanes by catalyst $[3]^{+}\left[\mathrm{BAr}_{4}^{\mathrm{F}}\right]^{-}$is sufficiently fluorophilic to hydrodefluorinate electron-rich $\mathrm{CF}_{3}$-substituted anilines (not shown). ${ }^{[12]}$ However, this catalysis required high catalyst loadings, an external base, and rather forcing reaction conditions. As such, we pursued the related activation of DIBAL-H for the same transformation under milder conditions. ${ }^{[14]}$ Activation of DIBAL-H at the $\mathrm{Ru}-\mathrm{S}$ bond led to the formation of adduct $\left[3 \cdot i \mathrm{Bu}_{2} \mathrm{AlH}\right]^{+}\left[\mathrm{B}\left(\mathrm{C}_{6} \mathrm{~F}_{5}\right)_{4}\right]^{-}$with chemical shifts for the hydride of $\delta\left({ }^{1} \mathrm{H}\right) \approx-12.0$ ppm and ${ }^{2} J_{\mathrm{H}, \mathrm{P}}$ coupling constants of $\sim 26$ $\mathrm{Hz}$. Detection of the sulfur-stabilized alumenium ion was not achievable. Similar to the activation of hydroboranes, ${ }^{[13]} \mathrm{ob}$ servation of the ${ }^{27} \mathrm{Al}$ nucleus $(I=5 / 2)$ by NMR spectroscopy failed because of high line width. Due to the enormous fluorophilicity of the generated alumenium ions, a change of counteranion to the more robust $\left[\mathrm{B}\left(\mathrm{C}_{6} \mathrm{~F}_{5}\right)_{4}\right]^{-}$, devoid of $\mathrm{C}\left(\mathrm{sp}^{3}\right)-\mathrm{F}$ bonds, was essential to reach high conversions. However, the dominant reaction pathway was the hydrodefluorination coupled with Friedel-Crafts benzylation of the arene solvent (Scheme 8). Several substituents in the $\mathrm{CF}_{3}$-containing substrates $\mathbf{2 0}$ were tolerated, and various electron-rich arenes 21 were converted into diarylmethanes $\mathbf{2 2}$ in high para:ortho ratios, usually above 70:30.

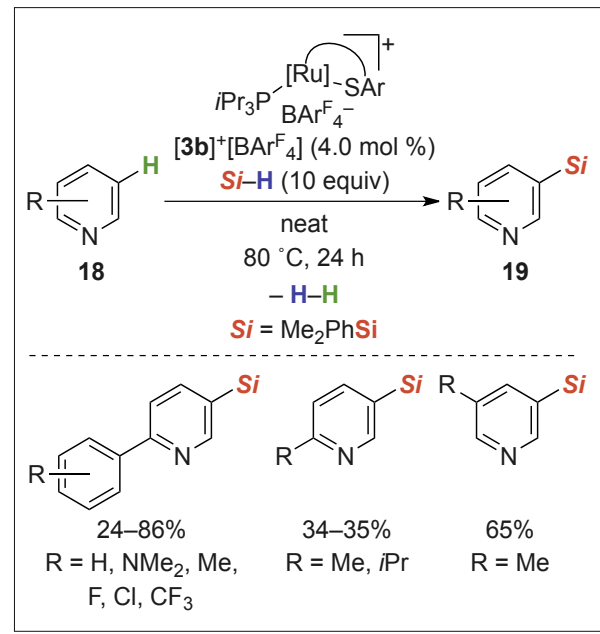

Scheme 7. Intermolecular formal electrophilic meta-C-H silylation of pyridines.

\section{Dehydrogenative Stannylation of C(sp)-H Bonds}

Exploring the cooperative activation of other main-group hydrides steered us toward hydrostannanes. ${ }^{[15]}$ These display markedly different reactivity compared to hydrosilanes, leading to fragile adducts. Nevertheless, NMR spectroscopic analysis of the hydrostannane adducts $\left[3 \cdot \mathrm{R}_{3} \mathrm{SnH}\right]^{+}[\mathrm{X}]^{-}$showed parallels to the activation of hydrosilanes: chemical shifts for the hydride of $\delta\left({ }^{1} \mathrm{H}\right) \approx-8.5 \mathrm{ppm}$ with ${ }^{2} J_{\mathrm{H}, \mathrm{P}}$ coupling constants of $\sim 48 \mathrm{~Hz}$. The corresponding sulfur-stabilized stannylium ions had chemical shifts of $\delta\left({ }^{119} \mathrm{Sn}\right)$ $\approx+155 \mathrm{ppm}$. This unprecedented catalytic generation of stannylium ions found application in dehydrogenative stannylations of terminal alkynes $\mathbf{2 3}$ (Scheme 9, left). In contrast to the hydrostannylation products 25 usually obtained from transition-metal catalysis with hydrostannanes, a broad scope of aryl-, alkyl-, silyl-, and vinylsubstituted alkynes $\mathbf{2 3}$ reacted smoothly to give dehydrocoupled $\mathbf{2 4}$ almost exclusively. To explain this high chemoselectivity we proposed catalytic intermediate $[\mathbf{2 6}]^{+}$, in which the stannylium ion is transferred to the $\mathrm{C}-\mathrm{C}$ triple bond to form a $\beta$-tin-stabilized vinyl cation, which likely adopts a bridged structure (Scheme 9, right). Subsequent abstraction of the proton $\alpha$ to the tin atom in $[26]^{+}$by the neutral ruthenium hydride 7 forms the alkynyl stannanes $\mathbf{2 4}$ and liberates dihydrogen.

\section{Conclusion}

The cooperative catalysis described herein is a powerful tool to form new carbon-main-group element bonds. Over the past decade, our laboratory succeeded in the generation of silylium, borenium, alumenium, and stannylium ions by heterolytic $\mathrm{E}-\mathrm{H}$ bond cleavage at $\mathrm{Ru}-\mathrm{S}$ bonds, and we have demonstrated the high reactivity of these main-group cations in various catalytic reactions. The low hydricity of the ruthenium(II) hydride with its adjacent basic sulfur ligand turned out to be crucial for efficient dehydrogenative couplings.

\section{Acknowledgements}

This research was in part supported by the Deutsche Forschungsgemeinschaft (Oe 249/8-1 and Oe 249/10-1). Additional support by the Cluster of Excellence Unifying Concepts in Catalysis of the Deutsche Forschungsgemeinschaft (EXC 314/2) is also acknowledged. M.O. is indebted to the Einstein Foundation (Berlin) for an endowed professorship. We are also grateful to Professors Ohki and Tatsumi for the fruitful collaboration and hosting stays of Dr. Hendrik F. T. Klare, Dr. Kristine Müther, and Dr. C. David F. Königs within the framework of the International Research Training Group Münster-Nagoya (GRK 1143 of the Deutsche Forschungsgemeinschaft).

Received: March 12, 2018

[1] For general reviews of metal-ligand cooperativity, see: a) J. R. Khusnutdinova, D. Milstein, Angew. Chem. Int. Ed. 2015, 54, 12236; b) R. Peters, 'Cooperative Catalysis', Wiley-VCH: Weinheim, 2015; c) H. Grützmacher, Angew. Chem. Int. Ed. 2008, 47, 1814.

[2] For general reviews of transition metal-sulfur complexes, see: a) T. B. Rauchfuss, Inorg. Chem. 2004, 43, 14; b) M. Breysse, E. Furimsky, S. Kasztelan, M. Lacroix, G. Perot, Catal. Rev.: Sci. Eng. 2002, 44, 651; c) P. J. Blower, J. R. Dilworth, Coord. Chem. Rev. 1987, 76, 121; d) M. R. Dubois, Chem. Rev. 1989, 89, 1.

[3] For reviews of hydrogenases, see: a) W. Lubitz, H. Ogata, O. Rüdiger, E. Reijerse, Chem. Rev. 2014, 114, 4081; b) J. C. Gordon, G. J. Kubas,

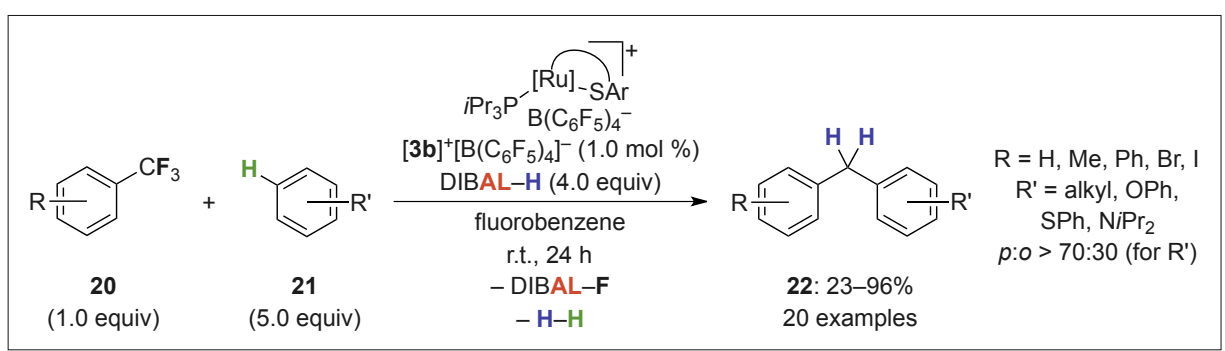

Scheme 8. Hydrodefluorinative Friedel-Crafts benzylation.

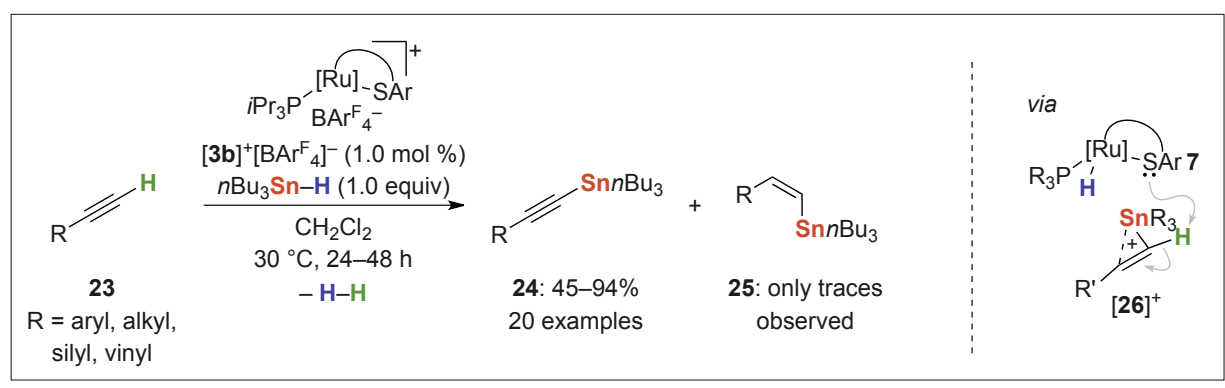

Scheme 9. Dehydrogenative stannylation of terminal alkynes. 
Organometallics 2010, 29, 4682; c) C. Tard, C. J. Pickett, Chem. Rev. 2009, 109, 2245.

[4] For reviews of transition-metal FLPs, see: a) H. Berke, Y. Jiang, X. Yang, C. Jiang, S. Chakraborty, A. Landwehr, Top. Curr. Chem. 2013, 334, 27; b) D. F. Wass, A. M. Chapman, Top. Curr. Chem. 2013, 334, 261; c) S. R. Flynn, D. F. Wass, ACS Catal. 2013, 3, 2574.

[5] J. J. Ellison, K. Ruhlandt-Senge, P. P. Power, Angew. Chem. Int. Ed. Engl. 1994, 33, 1178.

[6] a) Y. Ohki, M. Sakamoto, K. Tatsumi, J. Am. Chem. Soc. 2008, 130, 11610; b) for similar systems applied to $\mathrm{Si}-\mathrm{H}$ bond activation, see: K. D. Hesp, R. McDonald, M. J. Ferguson, M. Stradiotto, J. Am. Chem. Soc. 2008, 130, 16394.

[7] a) Y. Ohki, Y. Takikawa, H. Sadohara, C. Kesenheimer, B. Engendahl, E. Kapatina, K. Tatsumi, Chem. - Asian J. 2008, 3, 1625; b) A. Lefranc, Z.-W. Qu, S. Grimme, M. Oestreich, Chem. - Eur. J. 2016, 22, 10009.

[8] a) For a recent account of cooperative catalysis at metal-sulfur bonds focusing on $\mathrm{Si}-\mathrm{H}$ and B-H bond activation, see: L. Omann, C. D.
F. Königs, H. F. T. Klare, M. Oestreich, Acc. Chem. Res. 2017, 50, 1258; b) for a detailed analysis of the cooperative $\mathrm{Si}-\mathrm{H}$ bond activation at the Ru-S bond, see: T. Stahl, P. Hrobárik, C.

D. F. Königs, Y. Ohki, K. Tatsumi, S. Kemper, M. Kaupp, H. F. T. Klare, M. Oestreich, Chem. Sci. 2015, 6, 4324.

[9] a) H. F. T. Klare, M. Oestreich, J.-i. Ito, H. Nishiyama, Y. Ohki, K. Tatsumi, J. Am. Chem. Soc. 2011, 133, 3312; b) L. Omann, M. Oestreich, Angew. Chem. Int. Ed. 2015, 54, 10276; c) L. Omann, M. Oestreich, Organometallics 2017, 36, 767.

[10] a) C. D. F. Königs, H. F. T. Klare, Y. Ohki, K. Tatsumi, M. Oestreich, Org. Lett. 2012, 14, 2842; b) S. Bähr, M. Oestreich, Organometallics 2017, 36, 935; c) J. Hermeke, H. F. T. Klare, M. Oestreich, Chem. - Eur. J. 2014, 20, 9250; d) S. Wübbolt, M. S. Maji, E. Irran, M. Oestreich, Chem. - Eur. J. 2017, 23, 6213.

[11] a) C. D. F. Königs, H. F. T. Klare, M. Oestreich, Angew. Chem. Int. Ed. 2013, 52, 10076; b) S. Wübbolt, M. Oestreich, Angew. Chem. Int.
Ed. 2015, 54, 15876; c) S. Bähr, M. Oestreich, Chem. - Eur. J. 2018, 24, 5613.

[12] T. Stahl, H. F. T. Klare, M. Oestreich, J. Am. Chem. Soc. 2013, 135, 1248.

[13] T. Stahl, K. Müther, Y. Ohki, K. Tatsumi, M. Oestreich, J. Am. Chem. Soc. 2013, 135, 10978.

[14] F. Forster, T. T. Metsänen, E. Irran, P. Hrobárik, M. Oestreich, J. Am. Chem. Soc. 2017, 139, 16334.

[15] F. Forster, V. M. Rendón López, M. Oestreich, J. Am. Chem. Soc. 2018, 140, 1259.

[16] For recent reviews of C-H silylation, see: a) C. Cheng, J. F. Hartwig, Chem. Rev. 2015, 115, 8946; b) S. Bähr, M. Oestreich, Angew. Chem. Int. Ed. 2017, 56, 52.

[17] For a review of C-F bond activation, see: T. Stahl, H. F. T. Klare, M. Oestreich, ACS Catal. 2013, 3, 1578 . 